\title{
Gross Morphological Studies on Portal Vein in Adult Indian Sheep (Ovis aries)
}

\author{
B. Padmasri", G. Purushotham, D. Pramod Kumar, K. B. P. Raghavender and B. Swathi
}

Department of veterinary anatomy, College of veterinary science, Rajendranagar, Hyderabad-500030, India

*Corresponding author

\begin{tabular}{|c|c|}
\hline & A B S T RA C T \\
\hline Keywords & \\
\hline $\begin{array}{l}\text { Portal vein, Caudate } \\
\text { branch, Right } \\
\text { ventral intralobar } \\
\text { branches }\end{array}$ & \multirow{3}{*}{$\begin{array}{l}\text { The portal vein formed a guideline for passage of all vascular or nonvascular } \\
\text { structures in the extra and intrahepatic regions of the liver. It was divided into } \\
\text { caudate branch }(\mathrm{Cb}) \text {, right branch }(\mathrm{Rb}) \text { and left branch }(\mathrm{Lb}) \text {. The caudate branch } \\
\text { supplied entire caudate lobe and part of dorsal portion of the right lobe. The right } \\
\text { inter lobar branch was divided into right dorsal and right ventral intralobar } \\
\text { branches which supplied to respective regions of caudate lobe, right lobe and } \\
\text { quadrate area. The left inter lobar branch had a transverse part with its two major } \\
\text { branches the left dorsal and left ventral intralobar branches which supplied to } \\
\text { respective regions of left lobe and quadrate areas of the liver. }\end{array}$} \\
\hline Article Info & \\
\hline $\begin{array}{l}\text { Accepted: } \\
\text { 10 August } 2020 \\
\text { Available Online: } \\
10 \text { September } 2020\end{array}$ & \\
\hline
\end{tabular}

\section{Introduction}

Portal vein is the main afferent vessel that drains the nutrient loaded venous blood which contributes to $2 / 3$ of total hepatic blood flow. Portal venous blood has considerably more oxygen than the systemic venous blood and contributes $60 \%$ of the oxygen requirement of the liver (Cullen et al., 2016). 3/4 ${ }^{\text {th }}$ of the blood supply to liver is provided by portal vein. It is also to be understood that the periphery of the polyhedral lobule is not evenly supplied by portal venules and hepatic arterioles, although the hepatic sinusoids around the portal tracts are the sites where oxygen and nutrient rich blood flows first. Hepatic microcirculation is well regulated by sphincters in the finest branches of the portal venules and inlet venules.

\section{Materials and Methods}

The liver specimens along with portal vein were collected and their branching pattern was studied by infusion methods like corrosion cast technique using acrylic denture material (DPI-RR cold cure), contrast radiography by barium sulphate in glycerol and silicon gel technique (WACKER, GP general purpose silicon sealant).

\section{Results and Discussion}

The portal vein of liver in the present investigation was divided into caudate branch 
$(\mathrm{Cb})$, right branch $(\mathrm{Rb})$ and left branch $(\mathrm{Lb})$ (Fig. 1) which is similar to the observations of Franceschini and Ortale (1995) and Seo et al., (2001) who observed the trifurcation of portal vein into right, left and caudate branches in humans and cats respectively while Al-sadi (2013), Raut and Bahetee (2015) in humans and Al-sadi (2013) in sheep and goats who named these branches as right dorsal, right ventral and left branches whereas Rashad et $a l$. , (2017) termed these divisions as right, left and caudal omental in water buffaloes.

The present findings of trifuraction of portal vein in sheep is not in confirmation with the observations of Kalt and Stump (1993), Carlisle et al., (1995) in dogs, Arora et al., (2003) in humans, Anuradha and Singh (2004) in buffaloes, Ozudogru et al., (2005) in Van cats, Osman et al., (2008) in pigs, Maheswari (2011) in humans, Ranjbar and Ghadiri (2011) in Iranian Water Buffaloes, Rajput et al., 2014 in humans, Hall et al., (2015) in dogs, Georgiev et al., (2017) in humans as shorter right branch and longer and larger left branch. Paramo et al., (2017) in rabbits, Shrikantaiah et al., (2018) in humans have reported that there was a dichotomus branching and assigned different nomenclature to these branches as distributing veins, intrahepatic branches, portal branches, portal segments, interlobar branches etc.

Therefore, from the present study, it is noticed that the branching pattern of portal vein in the sheep liver is trichotomy which is contrary to the dichotomous pattern, quadrification and more than four branches as mentioned by the some of the researchers. All these variations in different species may be due to variation in development of the fissures in the liver and lobation pattern in different species which might be the basis for the dichotomus, trichotomus and quadrification divisions of the portal vein.
The caudate branch in the present study arose from the dorsal aspect of the main trunk of portal vein and traversed in dorsal direction towards the caudate lobe. The caudate branch appeared to be slender and shorter than the remaining two branches (Fig. 1). The caudate branch in the present investigation was observed dividing at its origin into two to three intra lobular branches which were further divided into innumerable branchings and rebranchings (Fig. 3). All these fine branches supplied to entire caudate lobe and also to a part of dorsal portion of the right lobe infront of the caudate lobe (Fig. 4). Similar findings were reported by Franceschini and Ortale (1995) in humans, where three divisions supplied to papillary process, vena cava region and caudate process while Tadialli and Akhavan (2003) in one humped camel reported that this branch supplied to caudate process and part of right lobe and Mogicato et al., (2015) in Beagle dogs observed the supply to papillary process without making any mention about the number of divisions arising from caudate branch whereas Martins and Neuhaus (2007) reported in rats, that it was very short and branched to supply anterior and posterior Spiegel lobe by two portal branches.

The right inter lobar branch was larger and traversed towards the lateral border and gave two major distributing veins, right dorsal and right ventral intralobar branches within the right lobe of the liver (Fig. 1 and 2) which is similar to the findings of Carlisle et al., (1995) in dogs where it was reported as right medial and lateral branches while Martins and Neuhaus (2007) reported in rats as superior and inferior branches and Al-Sadi (2013) in sheep and goats as right dorsal and ventral branches. The present observations are not in confirmity with Anuradha and Singh (2004) in buffalo, Ranjbar and Ghadiri (2011) in Iranian Water Buffaloes and Rashad et al., (2017) in water buffaloes where they have 
reported as three divisions called dorsal, intermediate and ventral interlobular veins while Shirai et al., (2005) in bovine reported as four major sub branches called superior, intermedius, inferior and processus caudate branches.

The right dorsal intra lobar branch immediately divided into fine multiple intra lobular branches to supply the dorsal part of right lobe near diaphragmatic surface of the liver and area in front of the caudate lobe. Then it continued as 4-5 small branches towards the lateral border in the dorsal portion of the right lobe and supplied the respective regions. These findings are in agreement with the observations of Ranjbar and Ghadiri (2011) in Iranian Water Buffaloes, where they reported that the right dorsal branch supplied to dorsal part of right lobe, papillary and caudate processes of caudate lobe while $\mathrm{Al}-$ sadi (2013) stated in sheep and goats that the right dorsal interlobular branch was short and large which supplied the caudate process and right dorsal hepatic lobe. The right ventral intra lobar branch traversed towards the ventral part of the right lobe and was divided into several small and fine intra lobular branches on its way to supply the quadrate area of the liver (Fig. 2).

These observations are in accordance with the reports of Ranjbar and Ghadiri (2011) in Iranian Water Buffaloes, who stated that the ventral branch was divided into three branches to supply the ventral parts of right and quadrate lobes while Al-Sadi (2013) stated in sheep and goats that the right ventral interlobular branch distributed only in the ventral part of the right lobe.

The transverse part of left interlobar branch in the present study was not only large but also longer than the remaining branches of the portal vein and this branch was partially embedded in the liver parenchyma. It gave several small branches to the papillary portion and part of right lobe also. This transverse part was continued towards the left lobe and divided into two major intra lobar distributing branches called left dorsal and ventral intralobar branches (Fig. 1).

Fig.1 Gross photograph of portal vein (corrosion cast) in sheep liver showing the PV (portal vein), $\mathrm{Cb}$ (caudate branch), $\mathrm{Rb}$ (right branch), Tp-Lb (transverse part-left branch), Ld (left dorsal), $\mathrm{Lv}$ (left ventral) and UF (umibilical fissure)

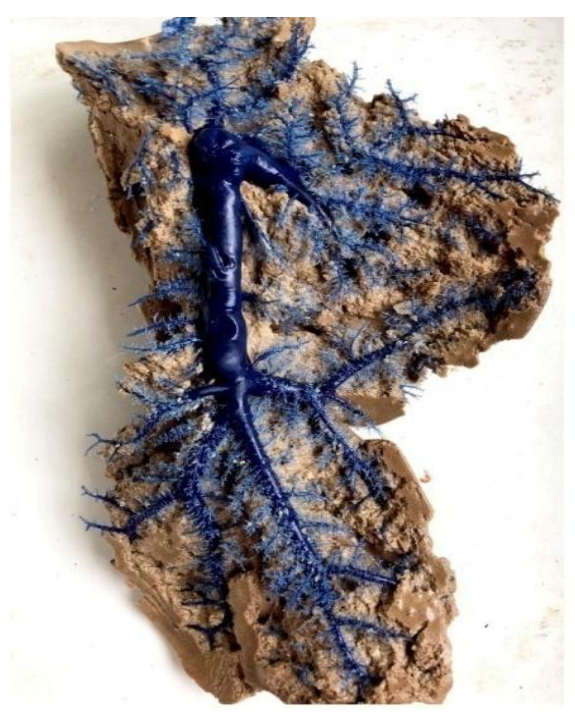


Fig.2 Gross photograph of silicon gel cast of portal vein in sheep liver showing $\mathrm{Cb}$ (caudate branch), Rb (right branch) Rd (right dorsal branch), Rv (right ventral branch) and Tp-Lb (left branch)

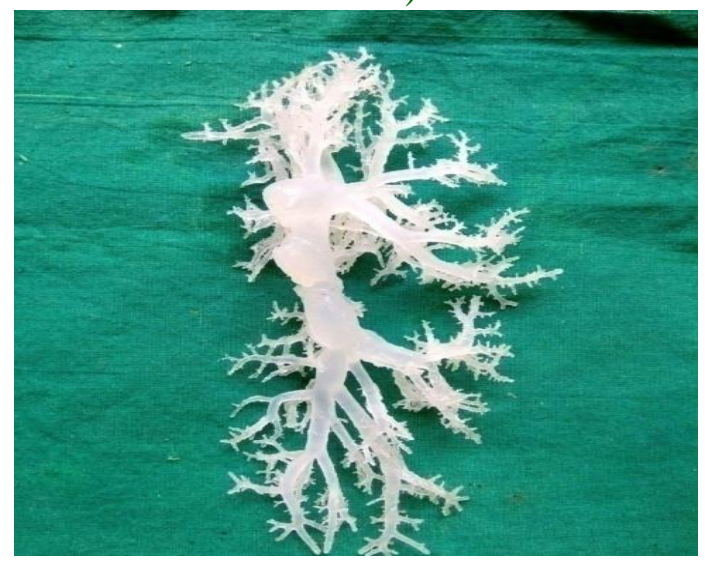

Fig.3 Grossphotograph of portal vein and bile duct (corrosion cast) in sheep liver showing the $\mathrm{PV}$ (portal vein), $\mathrm{Cb}$ (caudate branch), $\mathrm{Rb}$ (right branch), Tp-Lb (transverse part-left branch), Ld(left dorsal branch), Lv (left ventral branch), CBD(common bile duct) and their fine branches

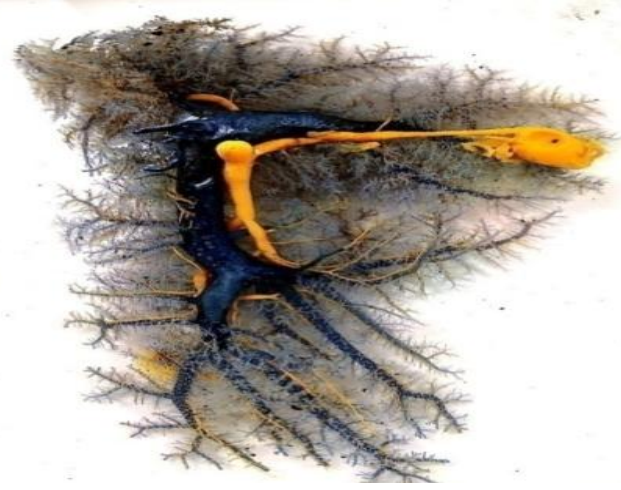

Fig.4 Contrast radiograph image of portal vein branches in sheep liver showing $\mathrm{Cb}$ (caudate branch), CL (caudate lobe), Rb (right branch), Rd (right dorsal branch), Rv (right ventral branch) branches, RL (right lobe), Tp-Lb (transverse part-left branch), Ld (left dorsal branch), Lv (left ventral branch) and LL (left lobe)

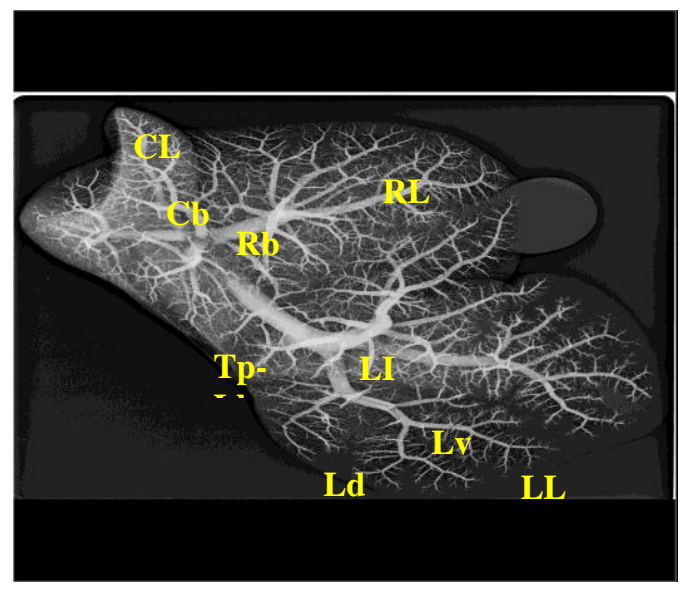


The present findings are in acceptance with the observations of Anuradha and Singh (2004) in buffaloes; Shirai et al., (2005) in bovine, Ranjbar and Ghadiri (2011) in Iranian water buffalo, Georgiev et al., (2017) in humans and Rashad et al., (2017) in water buffalo mentioned the branchings as pars transversa trunci sinistri (PTS) and pars umbilicalis trunci sinistri (PUS) which again gave rise to 3 to 5 small branches which supplied to respective regions of liver parenchyma. Further, Ranjbar and Ghadiri (2011) and Rashad et al., (2017) also explained that the transverse division gave several branches to papillary process of caudate lobe and quadrate lobe by omental and quadrate branches. They also reported that the umbilical division was divided into dorsal, intermediate and ventral interlobular branches to respective regions of the liver whereas Paramo et al., (2017) reported in rabbit liver that the left portal vein bifurcated into medial and lateral left portal vein.

The left dorsal intralobar branch in the present study was further divided into two branches. These intra lobular branches were divided and distributed extensively into multiple smaller branches to the level of finest venules to supply the dorso-medial portion and part of ventral borders of the left lobe of liver. The left ventral intra lobar branch arose at the level of the umbilical fissure in between the right and left lobes. This was short and bifurcated into two intra lobular branches at the umbilical fissure in dorsal and ventral directions. The branch which was traversing towards ventral portion of the left lobe of liver, subdivided into smaller branches in arborisation pattern and supplied to the remaining part of the left lobe. The other branch of left ventral intra lobar branch ran in dorsal direction and supplied the quadrate portion of the liver. All these branches further divided till smallest vessels (Fig. 1 and 3). Similar precise and extensive information on the branching pattern of left dorsal and ventral intralobar branches and their supply areas in the liver was not found in the literature reviewed. Some of the specimens in the present study had an intermediate branch that arose in oblique direction to the remaining two branches and supplied to the quadrate portion and left lobe nearer to its origin by several small branches (Fig. 4). Similar findings were also reported by Carlisle et al., (1995) in dogs, where it divided into left lateral, left medial and quadrate branches and supplied to respective regions. The present observations were contrary to the findings of several authors who have explained about the left branch getting divided into more than three branches as mentioned by Kalt and Stump (1993) who reported in dogs that left branch supplied right medial, quadrate, left medial, left lateral lobes including the papillary process of the caudate lobe. Further, Burton and White (1999) mentioned in neonatal dogs about the tertiary or quaternary arborization in portal vein while Tadialli and Akhavan (2003) reported in one humped camel that it supplied left lobe, right lobe, quadrate lobe and papillary process of caudate lobe, Ozudogru et al., (2005) in Van cat, supplied to right medial, quadrate, left lateral and left medial lobes, Osman et al., (2008) in pigs, supplied the left lateral, left medial and quadrate lobes whereas Al-Sadi (2013) observed in sheep and goats that it was long and narrow supplying to left and quadrate lobes including the papillary process while Hall et al., (2015) in dogs, supplied the left lateral, left medial, and quadrate lobes whereas, Biswas et al., (2018) in Ghungroo pigs stated that about its supply to left lateral and left medial lobes.

\section{References}

Al-Sadi, S. (2013). Anatomical and radiographic study of the portal and hepatic veins in Ovis Aris and Capras 
Hircus. The Iraqi Journal of Veterinary Medicine, 37(2), 244-250.

Anuradha, A., and Singh, O. (2004). Venography of intrahepatic portal veins of the liverin buffalo (Bubalus bubalis). The Indian Journal of Animal Sciences, 74(10).

Arora, J., Kapur, V., Kakkar, A., and Dixit, P. C. (2003). Ramification of portal vein in right lobe of liver-a corrosion casting study. J. Anat. Soc. India, 1, 1214.

Biswas, P., Ray, S., Das, P., Saren, S., Shee, A., Banerjee, A., and Islam, M. M. (2018). Gross Anatomical and Histomorphological Studies on Liver with Ramification of Portal Vein and Hepatic Artery in Ghungroo Pig. Int. J. Curr. Microbiol. App. Sci, 7(6), 29552965.

Burton, C. A., and White, R. N. (1999). The angiographic anatomy of the portal venous system in the neonatal dog. Research in veterinary science, 66(3), 211-217.

Carlisle, C. H., Wu, J. X., and Heath, T. J. (1995). Anatomy of the portal and hepatic veins of the dog: a basis for systematic evaluation of the liver by ultrasonography. Veterinary Radiology and Ultrasound, 36(3), 227-233.

Franceschini, L. J., and Ortale, J. R. (1995). Ramification of the portal vein at the portahepatis in humans. Surgical and Radiologic Anatomy, 17(1), 35-39.

Georgiev, G. I., Raychev, I., Mehandzhiyski, N., Hristakiev, L., Georgiev, G. D., and Sapundzhiev, E. (2018). Morphological studies of the canine hepatic portal system. Bulgarian Journal of Veterinary Medicine, 21(4).

Hall, J. L., Mannion, P., and Ladlow, J. F. (2015). Canine intrahepatic vasculature: is a functional anatomic model relevant to the dog. Veterinary Surgery, 44(1), 27-34.
Kalt, D. J., and Stump, J. E. (1993). Gross anatomy of the canine portal vein. Anatomia, histologia, embryologia, 22(2), 191-197.

Maheswari, K. (2011). Intrahepatic branching pattern of portal vein. Journal of Anatomical Society of India, 60(1), 5357.

Martins, P. N. A., and Neuhaus, P. (2007). Surgical anatomy of the liver, hepatic vasculature and bile ducts in the rat. Liver International, 27(3), 384-392.

Mogicato, G., Vautravers, G., MeynaudCollard, P., Deviers, A., and Sautet, J. (2015). Blood flows in tributaries of the portal vein: anatomical and angiographic studies in normal beagle dogs. Anatomia, histologia, embryologia, 44(6), 460467.

Osman, F. A., Wally, Y. R., El-Nady, F. A., and Rezk, H. M. (2008). Gross anatomical studies on the portal vein, hepatic artery and bile duct in the liver of the pig. J.Vet Anat, 1(1), 59-72.

Ozudogru, Z., Soyguder, Z., Aksoy, G., and Karadag, H. (2005). A macroscopical investigation of the portal veins of the Van cat. Vet Med Czech, 50(2), 77-83.

Páramo, M., García-Barquin, P., Santa María, E., Madrid, J. M., Caballeros, M., Benito,A., and Bilbao, J. I. (2017). Evaluation of the rabbit liver by direct portography and contrast-enhanced computed tomography: anatomical variations of the portalsystem and hepatic volume quantification. European radiology experimental, 1(1), 7.

Rajput, A. S., Kumari, S., and Mishra, G. P. (2014). A corrosion cast study of ramification pattern of portal vein in right lobe of human liver. Int J Anat Res, 2(4), 791-96.

Ranjbar, R., and Ghadiri, A. L. (2011). Observation of Intrahepatic Branching Pattern ofthe Portal Vein in Water 
Buffaloes of Iran. Asian Journal of Animal and Veterinary Advances, 6(5), 508-516.

Rashad, E., El-Haback, H. A., Abd Rabou, M. I., Hussein, S., and Khalifa, E. F. (2017). Gross Anatomy and Morphology of Egyptian Water Buffalo's Liver (Bubalus Bubalis) with Reference to some Histochemical and Immunohistochemical Evaluation. Research Journal of Pharmaceutical Biological and Chemical Sciences, 8(3), 45-60.

Raut, R. S., and Bahetee, B. H. (2015). Study of variations in the formation of portal vein. Sch. J. Appl. Med. Sci., 3, 13701375.

Seo, T. S., Oh, J. H., Lee, D. H., Ko, Y. T., and Yoon, Y. (2001). Radiologic anatomy of the rabbit liver on hepatic venography, arteriography, portography, and cholangiography. Investigative radiology, 36(3), 186-192. Shirai, W., Sato, T., Shibuya, H., Naito, K., and Tsukise, A. (2005). ThreeDimensional Vasculature of the Bovine Liver. Anatomia, histologia, embryologia, 34(6), 354-363.

Shrikantaiah, V. C., Basappa, M., Hazrika, S., and Ravindranath, R. (2018). Study of surgical anatomy of portal vein of liver segments by cast method and its clinical implications. Anatomy and cell biology, 51(4), 232-235.

Tadialli, M., and Akhavan, R. (2003). Anatomical study on intrahepatic branches of portal vein in one humped camel (Camelus dromedarius). Journal of Camel Practice and Research, 10(2), 201-206.

\section{How to cite this article:}

Padmasri, B., G. Purushotham, D. Pramod Kumar, K. B. P. Raghavender and Swathi, B. 2020. Gross Morphological Studies on Portal Vein in Adult Indian Sheep (Ovis aries). Int.J.Curr.Microbiol.App.Sci. 9(09): 943-949. doi: https://doi.org/10.20546/ijcmas.2020.909.116 